10

\title{
Акустическое тестирование в технологии производства строительной керамики с упрочняющими добавками
}

\author{
() Р.М. Нафикков, ${ }^{1}$ Г.Р. Фасеева, ${ }_{1}^{1}$ Ю.В. Лысогорский, ${ }_{1}^{1}$ Ю.А. Захаров, ${ }_{1}^{1}$ Р.Р. Кабиров ${ }^{2}$ \\ ${ }^{1}$ Институт фризики, Казанский (Приволжский) федеральный университет, \\ 420008 Казань, Россия \\ ${ }^{2}$ Открытое акционерное общество „Алексеевская керамика“, \\ 422900 Алексеевское, Татарстан, Россия \\ E-mail: zaha1964@yandex.ru
}

Поступило в Редакцию 19 мая 2018 г.

В окончательной редакции 22 мая 2019 г.

Принято к публикации 28 августа 2019 г.

\begin{abstract}
Интерпретировано поведение звукового спектра свободных колебаний цилиндрических образцов керамики для светло-желтого лицевого кирпича в зависимости от условий обжига, а также от упрочняющих добавок мелкодисперсных отходов стекловолокна. Выявлена корреляция частот и времени релаксации колебаний с внутренними дефектами и прочностью на сжатие и изгиб. Предложена методика тестирования, снижающая издержки промышленного масштабирования такой технологии упрочнения строительной керамики.
\end{abstract}

Ключевые слова: строительная керамика, акустический контроль, прочность, дефектность.

DOI: $10.21883 /$ JTF.2020.02.48825.199-18

\section{Введение}

Повышение прочности строительной керамики (кирпича, черепицы, плитки) достигается внесением в глинистое сырье мелкодисперсных, в том числе наноразмерных модифицирующих добавок различного происхождения $[1,2]$. В процессе обжига компоненты шихты спекаются друг с другом, формируя керамический каркас изделия, в котором по разным причинам появляются микро- и макроскопические дефекты в виде каверн, трещин и расслоений. При неправильном обжиге добавка заведомо упрочняющего модификатора может привести к обратному эффекту - браку, например, к вспучиванию кирпича выделяемыми газами (рис. 1, $a$ ). Подобные эксперименты с добавками в производственных условиях слишком рискованны и затратны. Поэтому технологию отрабатывают на лабораторных миниатюрных образцах изделий, а затем масштабируют.

Традиционно измеряемая на прессе сила разрушения случайно выбираемых образцов из приготовленной для разнообразных испытаний партии является интегральной характеристикой противодействующих вкладов в прочность со стороны модификатора и дефектов. Поэтому по ней трудно оценивать эффективность модификатора, выявлять тип дефекта и соответственно проводить оптимизацию технологии, которая является многопараметрической. В данном случае можно применять предварительное неразрушающее акустическое тестирование [3-9] всей партии образцов. Причем метод свободных низкочастотных колебаний [3] благодаря аппаратной простоте выглядит предпочтительнее других. С его помощью налажена отбраковка черепицы [10-12], определяется марка кирпича [13], изучается обжиг керамики [14-16]. Однако применение этого метода сдер- живается сложностью интерпретации связи звуковых сигналов с прочностью соответствующих образцов из-за их непредсказуемой слоистости, пористости и трещиноватости.

Целью настоящей работы является внедрение акустического контроля в производство строительной керамики на основе исследования корреляции звукового спектра с прочностью лабораторных цилиндрических образцов керамики для лицевого кирпича, модифицируемой упрочняющими добавками измельченных отходов стекловолокна.

\section{1. Методика проведения эксперимента}

Использовали смесь глин для лицевого кирпича марки М150 цвета „слоновая кость“ (ОАО „Алексеевская керамика“). Состав шихты приведен в [17]. В нее добавляли упрочняющий модификатор (отход Елабужского завода стекловолокна) в количестве 2.5 и $5 \%$ mass. (далее $\mathrm{m} \%)$ - порошок перемолотых волокон диаметром до $100 \mu \mathrm{m}$, содержащий (в $\mathrm{m} \%): \mathrm{SiO}_{2}-53, \mathrm{CaO}-17$, $\mathrm{Al}_{2} \mathrm{O}_{3}-15, \mathrm{~B}_{2} \mathrm{O}_{3}-10, \mathrm{MgO}-4, \mathrm{Na}_{2} \mathrm{O}-0.3, \mathrm{Fe}_{2} \mathrm{O}_{3}-0.1$, прочие - 0.6. Формовочная влажность шихты $21 \mathrm{~m} \%$. Формовали образцы диаметром $30 \mathrm{~mm}$ и длиной $125 \mathrm{~mm}$ (pис. $1, b, c$ ) на вакуумном экструдере Verdes-050 [17]. Цилиндрические образцы лучше прямоугольных тем, что не имеют углов и соответствующих механических напряжений с дефектами, усложняющими интерпретацию спектра, и теория колебаний цилиндра детально разработана $[18,19]$. Использовали заводские камерные сушила, поднимая температуру в них с 30 до $80^{\circ} \mathrm{C}$ в течение $63 \mathrm{~h}$. Часть сырцов высушивали с нарушением этого режима для получения заведомо потрескавшихся 

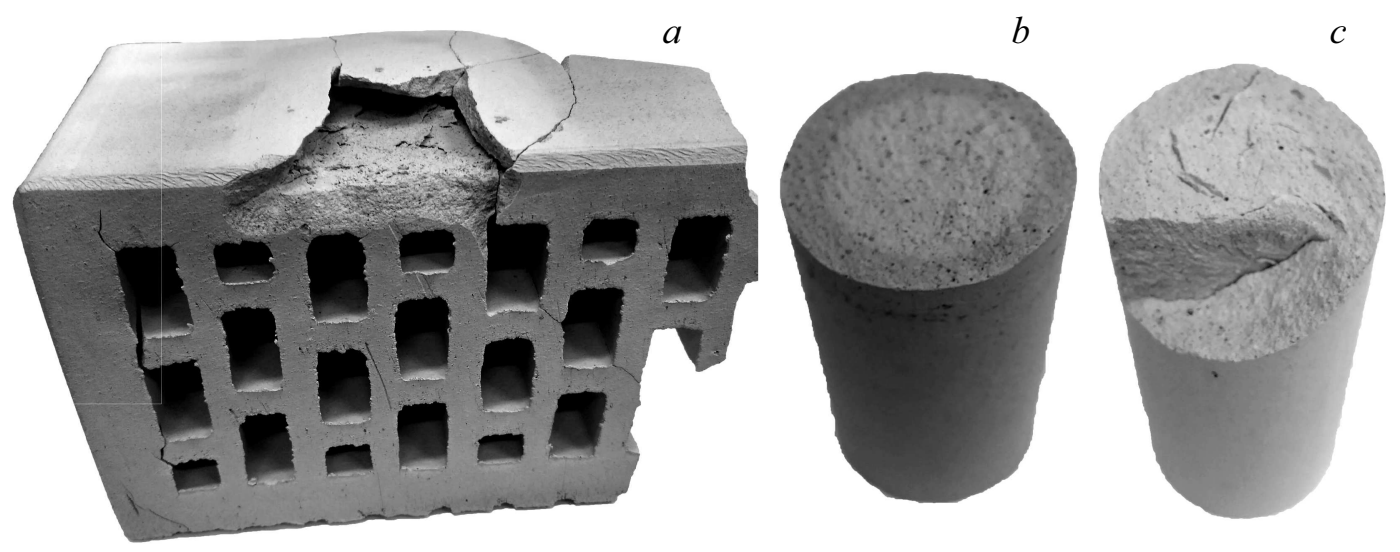

Рис. 1. Строительная лицевая керамика цветовой марки „слоновая кость“: $a$ - брак вспучивания кирпича; сломанные лабораторные образцы диаметром $30 \mathrm{~mm}$ с недожженной темной (розоватой) оболочкой $(b)$ и с окончательно обожженной оболочкой, но с вытянутыми кавернами $(c)$.

экземпляров. Образцы обжигали в заводской, камерной, газовой печи, нагревая до $1050^{\circ} \mathrm{C}$ за $17 \mathrm{~h}$, выдерживая $7 \mathrm{~h}$ и затем охлаждая за $12 \mathrm{~h}$ до $50^{\circ} \mathrm{C}$. Минеральный состав получаемых образцов описан в [17].

Силу $F_{p}$, разрушающую образец при сжатии, измеряли на прессе ПГМ-500МГ4 при нагрузке $1 \mathrm{MPa} / \mathrm{s}$ [20]. Цилиндр распиливали поперек и получали 3 части длиной $30 \mathrm{~mm}$. Их сжимали отдельно друг от друга, а результаты усредняли и брали за характеристику целого образца. Погрешность пресса не превышала $3 \%$. Силу $F_{f}$, разрушающую образец при изгибе, определяли, устанавливая его на опорах с промежутком $100 \mathrm{~mm}$ и прикладывая нагрузку $0.1 \mathrm{MPa} / \mathrm{s}$ в центр [20].

Самодельный акустический спектрометр представлял собой платформу с двумя парами стоек, связанных свисающими нитями для подвешивания образца. Полиэтиленовый шарик диаметром $15 \mathrm{~mm}$, прикрепленный на пружине к платформе, отклоняли пальцем и отпускали так, что удар приходился в центр торца цилиндра. Звук с частотой дискретизации $44 \mathrm{kHz}$ записывался компьютером через микрофон у другого торца. Программа на языке Wolfram Mathematica осуществляла фурьепреобразование сигнала в интервале $0-20 \mathrm{kHz}$, измеряла частоты колебаний цилиндра $v_{i}$, строила зависимости их амплитуды от времени и вычисляла времена релаксации $\tau_{i}$. Минимальный интервал разбиения звукового сигнала $6 \mathrm{~ms}$. Минимальное интегрирование сигнала по времени $6 \mathrm{~ms}$ и по частоте $1 \mathrm{~Hz}$. Относительное стандартное отклонение $v_{i}$ при пятикратном помещении на штатив одного и того же цилиндра не превышало $0.05 \%$.

\section{2. Экспериментальные результаты и их обсуждение}

\section{1. Акустические спектры образцов}

Изготовили три серии образцов из 10-13 штук с разным содержанием модификатора. Они получились желтого цвета, близкого к слоновой кости и слегка отличались кремовым тоном. Исключение составил один цилиндр с розоватым оттенком (рис. $1, b)$ в серии без модификатора. Он оказался в зоне печи с локально повышенным содержанием кислорода и пониженной температурой из-за близости открытого люка для термопары. Известно, что желтый цвет лицевой керамики зарождается внутри образца и выходит на поверхность при максимальной температуре обжига, сменяя первоначально красный цвет. При этом прочность падает, но обеспечивается товарная привлекательность равномерной окраски под слоновую кость. То есть розоватый экземпляр не обжегся до конца. Его спектр существенно отличался от остальных и поэтому не брался в расчет при статистической обработке. Осциллограммы звука розоватого, кремового и желтого образцов показаны на рис. 2. Они демонстрируют биения - признак неоднородной внутренней структуры. Соответствующие спектры даны на рис. $3 a, d, g$. При малом разрешении проявляются два интенсивных пика. Первый по амплитуде с частотой $v_{1} 5-8 \mathrm{kHz}$ дает изгибные колебания цилиндра, второй с $v_{2} 15-18 \mathrm{kHz}$ результат сжатия/растяжения [18,21]. Между ними наблюдается слабый пик крутильных колебаний. При высоком разрешении видна двухкомпонентность спектральных линий. Это свидетельствует о том, что керамический цилиндр состоит из разных по упругости сердцевины и оболочки. Они различимы по цвету на сколе цилиндра. Рис. 4 четко благодаря разбиению сигнала на интервалы $21 \mathrm{~ms}$ точками показывает динамику затухания интегральной по частоте громкости $A_{\text {int }}$ линий $v_{1}$ и $v_{2}$ в спектрах на рис. 3 соответственно. Но такого разбиения недостаточно для разрешения и отдельного описания очень близких спектральных компонент. Поэтому при аппроксимации этих точек экспонентой, хорошо описывающей колебания однородного цилиндра, они не ложатся на нее в случаях рис. 4, $a, c, e, f$, а рисуют биения. Только 

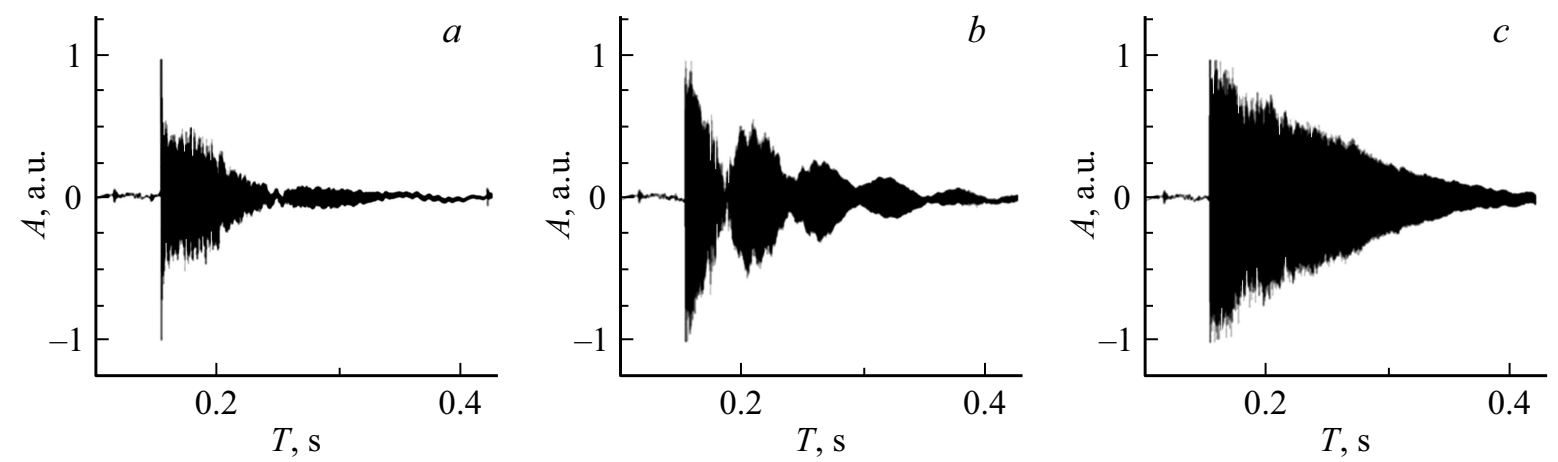

Рис. 2. Осциллограммы типичных звуковых сигналов цилиндров из лицевой керамики $a-$ розового оттенка, $b-$ кремового оттенка, $c$ - чисто желтого цвета.
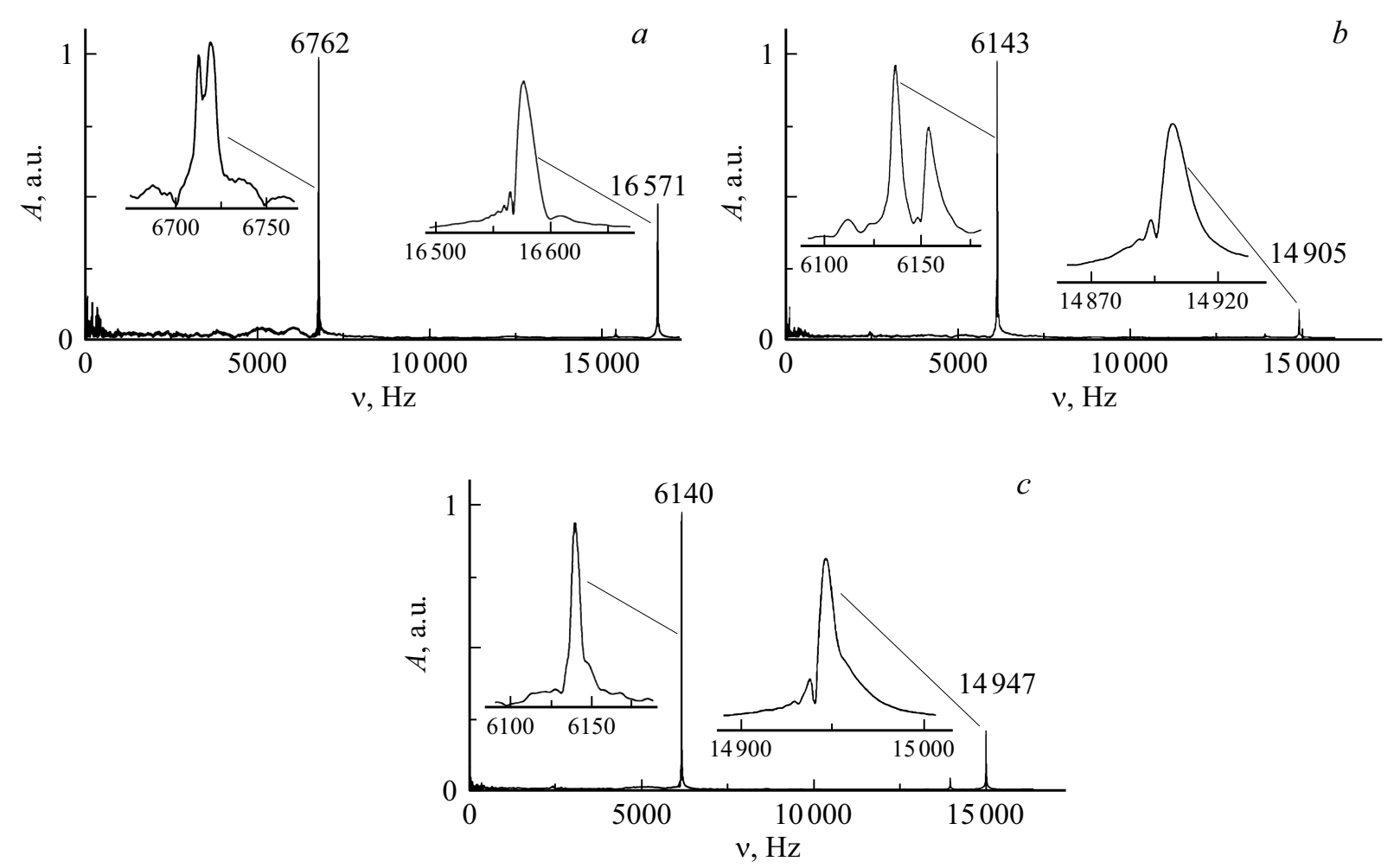

Рис. 3. Спектры звуковых сигналов, показанных на рис. 2 соответственно.

на рис. $4, b$ и $d$ они удовлетворительно совпали, так как одна из компонент существенно преобладает над другой.

Можно предположить, что первоначально более интенсивная правая компонента спектральной линии $6762 \mathrm{~Hz}$ (рис. 3,a) принадлежит оболочке, а левая сердцевине. По мере обжига и превращения розового образца в кремовый оболочка постепенно выгорает, и ее частота смещается влево до $6143 \mathrm{~Hz}$ вместе с компонентой увеличивающегося по объему, но одновременно теряющего прочность сердечника. При этом разница частот этих компонент увеличивается с 8 до $17 \mathrm{~Hz}$. Обжиг образца до конечного желтого цвета свел к минимуму вклад оболочки в его прочность и соответственно в акустический спектр. Действительно, правые компонен- ты спектральных линий почти исчезли на фоне левых (рис. 3,c) и разница частот компонент упала до $5 \mathrm{~Hz}$ из-за выравнивания упругости по объему цилиндра.

Разрешения спектрометра для захвата тонких компонент спектральных линий розоватого и желтых образцов недостаточно, чтобы рассчитать их индивидуальные $\tau_{i}$. Поэтому он выдает „эффективные“ $\tau_{i}$. Тем не менее у более прочных и звонких розоватого и кремового образцов без модификатора они примерно в 1.5 раза меньше, чем у остальных цилиндров. Это объясняется тем, что пока связанные осцилляторы (сердцевина и оболочка) эквивалентны по мощности они наиболее сильно гасят колебания друг друга из-за несовпадения собственных частот. Так как компоненты спектральных линий кре- 

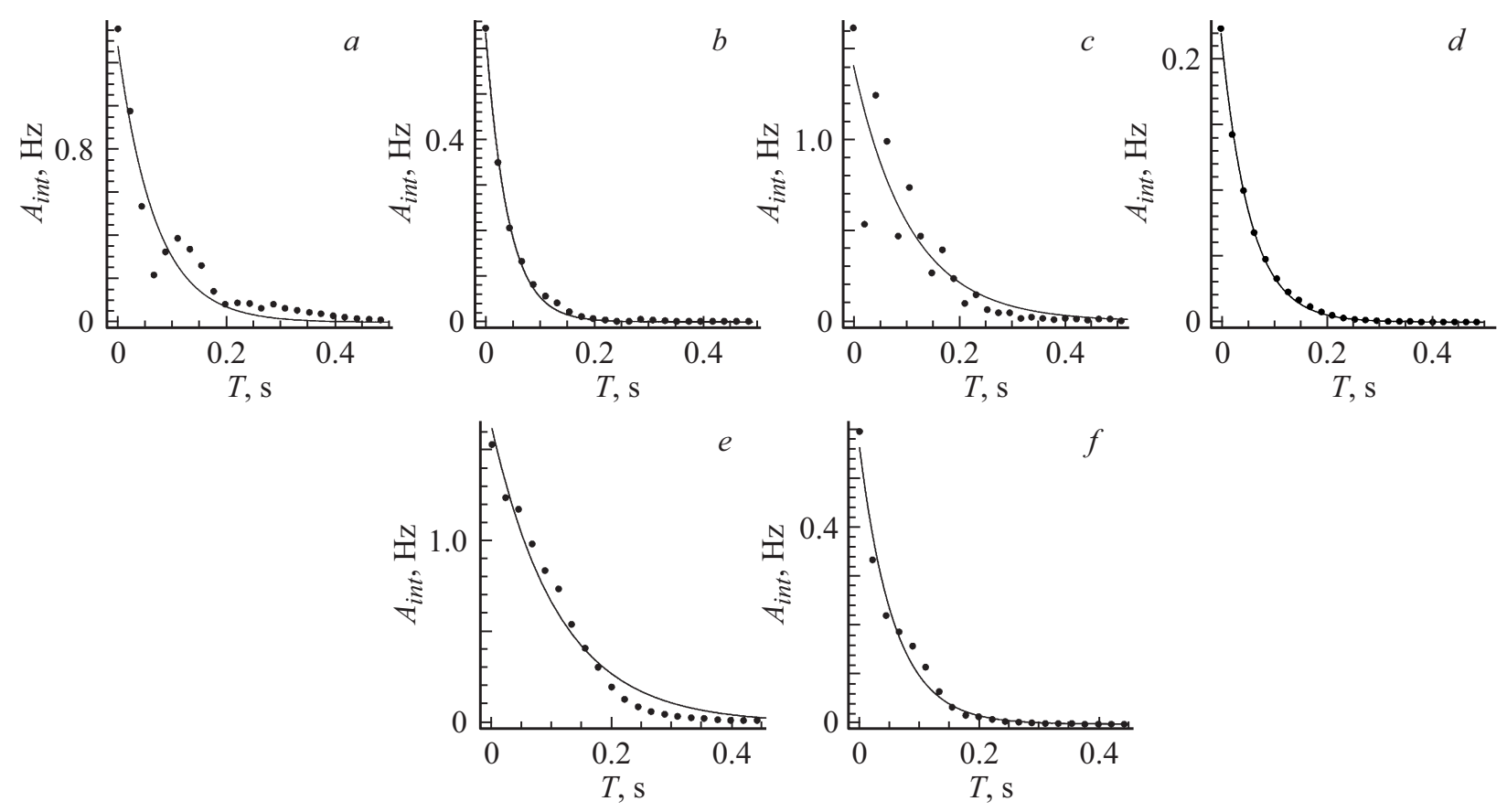

Рис. 4. Затухание интегральной по частоте амплитуды $A_{\text {int }}$ первой $(a, c, e)$ и второй $(b, d, f)$ по интенсивности линий в спектрах на рис. 3 соответственно.

мового образца успешно выделяются программой при интервале разбиения звукового сигнала $0.021 \mathrm{~s}$ удалось измерить их $\tau_{i}$ : у левой $-105 \mathrm{~ms}$, у правой $-44 \mathrm{~ms}$.

\section{3. Реакция спектральных линий на модификатор}

В каждой серии образцов разница между максимальной и минимальной частотой линии составляет от 152 до 996 Hz. В то же время среднеквадратическое отклонение частоты меньше $1 \%$. У заведомо дефектных цилиндров оно резко возросло, частоты колебаний уменьшились, $\tau_{i}$ сократились. Образцы с видимыми трещинами вообще не давали спектральных линий. Следовательно, спектрометр способен реагировать на весьма тонкие различия даже у однотипных визуально неотличимых образцов. Если образцы расставить по убыванию $v_{1}$, то $v_{2}$ будет убывать так же. Но есть редкие исключения, повидимому, обусловленные ориентированными микротрещинами или кавернами в образцах, либо структурными неоднородностями керамики, которые по-разному влияют на продольные и поперечные колебания. Необходимо отметить, что нарушения расположения $v_{2}$ в убывающем порядке обусловлены незначительной разницей $1-2 \%$. Вычисленные с интегрированием в интервале $\pm 48 \mathrm{~Hz}$ $\tau_{i}$ у однотипных образцов не обнаруживают явной корреляции с $v_{i}$. У поперечных колебаний всех цилиндров они составляют в среднем $100 \mathrm{~ms}$ и примерно в два раза больше, чем у продольных, независимо от количества введенного модификатора. Получается так, что продольные колебания теряют энергию быстрее, чем изгибные.
Следовательно, $\tau$ можно рассматривать как индикатор состояния керамики. Однако явной корреляции $\tau$ с добавками модификатора не обнаружено.

\section{1. Влияние модификатора на прочность образцов}

Из каждой серии случайно отобрали по три цилиндра для испытаний на прессе. Построили зависимости $F_{p}$ и $F_{f}$ от количества модификатора, используя их минимальные, средние и максимальные значения (рис. 5). Так, графики 1-3 прочности на сжатие на рис. 5, $a$ приводят к разным выводам: 1) 5 m\% модификатора упрочняет керамику хуже, чем $2.5 \mathrm{~m} \%$; 2) зависимость после добавки 2.5 m\%. переходит в насыщение; 3) с увеличением модификатора прочность монотонно растет. Графики 1-3 изгибных испытаний на рис. 5, $b$ не дают даже намека на насыщение и тем более на ослабление прочности с увеличением модификатора.

Используем результаты акустического тестирования, чтобы прояснить ситуацию. На рис. 6 сплошными символами показаны измеренные на прессе прочности образцов с разными добавками модификатора и их частоты. Эти зависимости аппроксимировали прямыми, а уравнения записали в таблицу. Подставляя $v_{1}$ и $v_{2}$ в уравнения, рассчитали $F_{p}$ и $F_{f}$, значения которых нанесли пустыми символами на рис. 6.

\section{2. Тестирование прочности на сжатие}

Разница между максимальной и минимальной прочностями в каждой серии модифицированных образцов в 

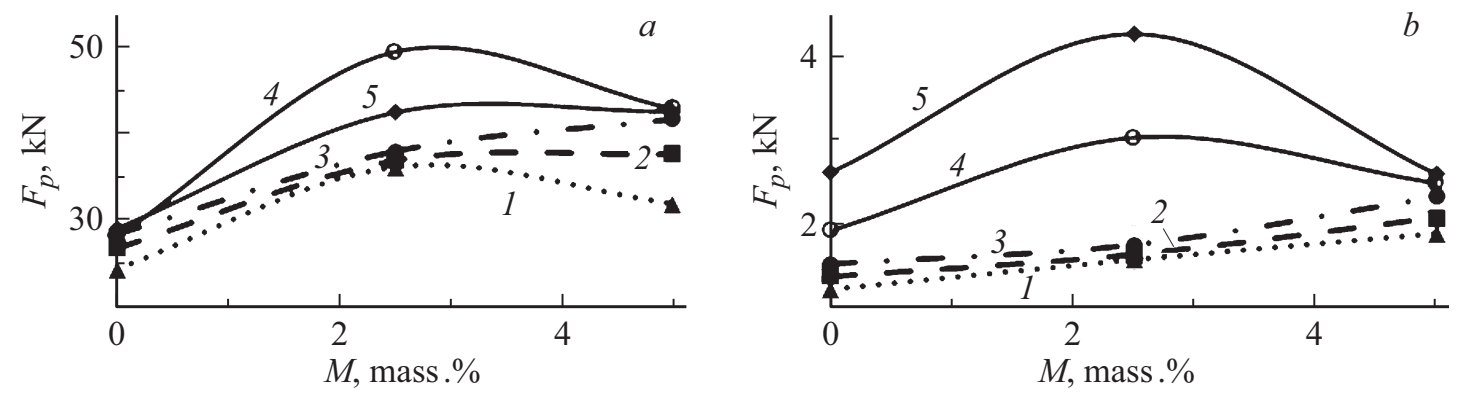

Рис. 5. Зависимости разрушающих сил на сжатие $(a)$ и изгиб $(b)$ от количества $M$ модификатора в образце: 1 - минимальные, 2 - средние и 3 - максимальные значения $F_{p}$ и $F_{f}$; расчетные максимальные значения $4-F_{p}$ и $5-F_{f}$.
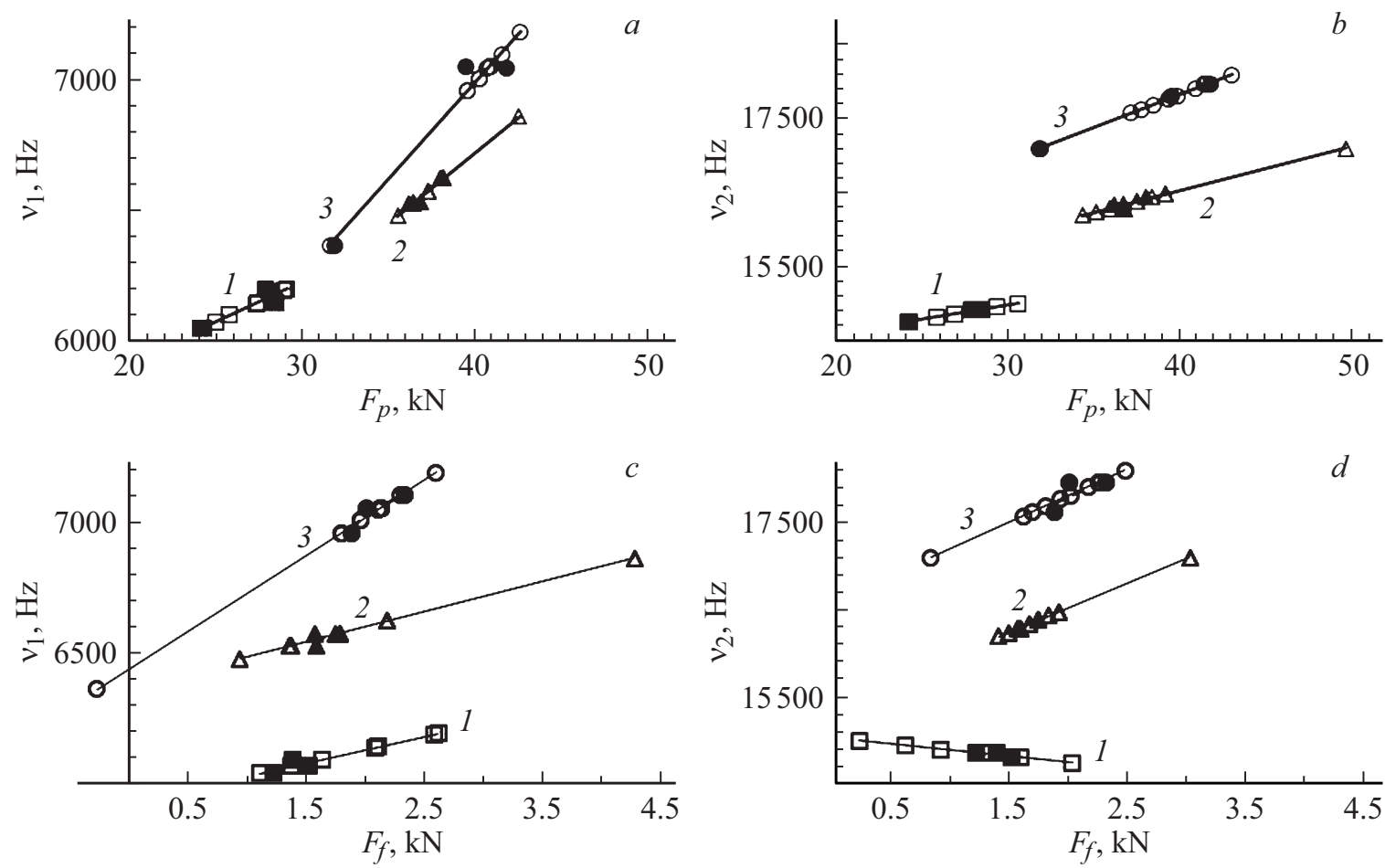

Рис. 6. Связь между разрушающей силой на $a, b-$ сжатие $F_{p}, c, d-$ изгиб $F_{f}$ и частотами $a, c-$ поперечных и $b, d-$ продольных колебаний цилиндров с содержанием модификатора: $1-0,2-2.5,3-5 \mathrm{~m} \%$. Сплошные символы - испытания на прессе, пустые - расчет.

два-три раза больше, чем в исходной. Она свидетельствует о более высокой чувствительности таких изделий к отклонениям от технологии (по полю температур в сушилах и печи, составу их атмосфер, флуктуациям параметров формовки). Действие модификатора наилучшим образом характеризуют максимально прочные образцы, так как они в силу обстоятельств оказались менее дефектными.

Коэффициенты наклона графиков функций в таблице по мере увеличения номера возрастают, в конечном счете, более чем в два раза. При этом $\tau$ остается на прежнем уровне, что свидетельствует о наличии дефектов не в виде трещин, а в виде замкнутых полостей. Известно [22], что под действием данного модификатора наблюдается структурная перестройка керамики.
Частицы модификатора превращаются в полые жеодыконкреции, вросшие в основную мелкопористую керамическую массу. С другой стороны, модификатор снижает газопроницаемость исходной керамики, которая из-за высокого содержания карбонатов при обжиге выделяет оксид углерода. Собственно, это привело к вспучиванию полноформатного кирпича при заводском эксперименте с модификатором без коррекции действующей технологии. На спилах и сколах модифицированных лабораторных образцов тоже обнажались характерные полости от вспучивания.

Рис. 6 показывает, что метод оценки прочности на слух по звону от удара работает только в пределах одной партии кирпича. Более звонкий кирпич из другой шихты может оказаться менее прочным. Сравнивая ко- 
Уравнения аппроксимации графиков на рис. 6

\begin{tabular}{c|c|c|c|c}
\hline № & $a, v_{1}=$ & $b, v_{2}=$ & $c, v_{1}=$ & $d, v_{2}=$ \\
\hline 1 & $30.533 F_{p}+5307.0$ & $38.727 F_{p}+13814$ & $100.64 F_{f}+5931.8$ & $-136.47 F_{f}+15029$ \\
\hline 2 & $54.102 F_{p}+4556.1$ & $59.242 F_{p}+14159$ & $114.16 F_{f}+6369.9$ & $554.83 F_{f}+15415$ \\
\hline 3 & $74.280 F_{p}+4016.2$ & $89.147 F_{p}+14260$ & $285.6 F_{f}+6442.5$ & $600.91 F_{f}+16601$
\end{tabular}

эффициенты наклона прямых с одинаковыми номерами в таблице, можно отметить, что $v_{2}$ чуть сильнее реагирует на изменение прочности. Диапазон этих коэффициентов от 30 до $89 \mathrm{~Hz} / \mathrm{kN}$ демонстрирует высокую чувствительность смещения спектральных линий к изменению прочности на сжатие лицевой керамики одного сорта изза флуктуаций технологических параметров. Кривые 4 и 5 на рис. 5, $a$, построенные по максимальным значениям расчетной прочности для $v_{1}$ и $v_{2}$, однозначно указывают на то, что оптимальной является добавка 2.5 m\% модификатора, хотя вычисленные значения прочности заметно отличаются друг от друга, очевидно, из-за погрешности аппроксимации. Итак, акустическое тестирование четко указывает на две перспективы оптимизации технологии: 1) можно удвоить прочность на сжатие введением $2.5 \mathrm{~m} \%$ модификатора без изменения других технологических параметров, 2) можно добиться большего упрочнения добавкой $5 \mathrm{~m} \%$, но при изменении этих параметров.

\section{3. Анализ прочности на изгиб}

Из рис. $6, c, d$ и таблицы видно, что $v$ растет с увеличением изгибной прочности. Диапазон соответствующих коэффициентов наклона составляет $100-600 \mathrm{~Hz} / \mathrm{kN}$, что демонстрирует более высокую чувствительность смещения спектральных линий к изменению прочности на изгиб лицевой керамики одного сорта из-за флуктуаций технологических параметров, чем при сжатии. Исключение составляет график 1 на рис. $6, d$, где наблюдается странный наклон в другую сторону. Вероятно, это результат случайной погрешности данного теста, как следствие неполноценности испытаний на прессе ограниченного числа образцов из серии. Отрицательное значение минимальной прочности на графике 3 рис. 6, $c$ тоже результат погрешности аппроксимации по случайно выбранным калибровочным образцам. В свою очередь акустическое тестирование указывает на наличие хаотично расположенных дефектов-каверн внутри образцов, которые не уменьшают интенсивность колебаний, но могут сильно снизить изгибную прочность, оказавшись в центре испытуемого цилиндра, куда давит пресс.

Графики 4 и 5 на рис. $5, b$ показывают, что добавка $2.5 \mathrm{~m} \%$ тоже оптимальна. Обращает внимание заметная разница в значениях прочности, рассчитанных по разным спектральным линиям. Видимо, это следствие погрешности аппроксимации. Разница должна исчезнуть, если для пресса отбирать образцы после акустического тестирования с минимальной, средней и максимальной $v_{1}$, а не случайно, как в данном случае. Наиболее прочные образцы с добавкой 2.5 m\% явно выбиваются из общей группы, следовательно, технология имеет потенциал, который можно раскрыть путем оптимизации. Эксперимент показывает, что для эффективного применения данного модификатора необходимо уменьшить скорость нагрева печи на этапе разложения карбоната кальция, и тем самым обеспечить выход газов из изделия без вспучивания. Этот интервал обжига полноформатного кирпича можно точно выявить с помощью специально модифицированной муфельной печи [23].

\section{4. Методика акустического контроля технологии}

Изготавливают серии из 10-20 лабораторных образцов, снимают их акустические спектры, измеряют частоты колебаний и релаксацию. Делают выводы об оболочке. Если среднеквадратическое отклонение частот меньше $2 \%$, то берут образцы для пресса, если больше, то образцы бракуются. Испытывают на прессе образцы с минимальной, средней и максимальной $v_{1}$ и строят графики типа рис. 6. По наклону графиков у серий образцов диагностируют дефекты. По диапазону значений прочности в серии выясняют чувствительность изделия к флуктуациям технологических параметров. Строят график зависимости максимальных значений прочности от добавки модификатора и выявляют его упрочняющее действие. График, построенный по минимальным значениям, сравнивают с предыдущим и оценивают падение эффективности модификатора из-за технологических флуктуаций. Целенаправленно оптимизируют технологию.

\section{Заключение}

Широкая практика использования различных добавок в глинистое сырье при производстве строительных керамических материалов с целью улучшения качества продукции, а также для попутной утилизации промышленных и бытовых отходов требует объективного контроля изменения прочности выпускаемых изделий. Проведенное исследование показало, что акустическое тестирование лабораторных керамических образцов цилиндрической формы методом свободных колебаний позволяет 
чувствительно выявить, как изменение прочности, так и диагностировать характер внутренних, скрытых от визуального обнаружения дефектов. В звуковом спектре цилиндрических образцов керамики для желтого лицевого кирпича наблюдаются две интенсивные линии продольного и поперечного колебаний, которые смещаются при изменении прочности на сжатие с коэффициентами $30-89 \mathrm{~Hz} / \mathrm{kN}$, а на на изгиб $100-600 \mathrm{~Hz} / \mathrm{kN}$ при прочностях испытанных образцов, достигающих 50 и $5 \mathrm{kN}$ соответственно. Положение линий чувствительно реагирует не только на добавку модификатора в несколько процентов, но даже на флуктуации технологических параметров изготовления образцов (температуры обжига, состава атмосферы печи и др.). Многокомпонентность отдельных спектральных линий, а также биения на кривых их затухания указывают на наличие у образцов сердцевины и оболочки, разных по упругости. Время релаксации изгибного колебания у наиболее качественных образцов достигает в среднем $100 \mathrm{~ms}$, а продольного - $50 \mathrm{~ms}$, независимо от количества введенного модификатора и наличия каверн. Однако оно устремляется к нулю при возникновении трещин. Это позволяет достоверно диагностировать подобные дефекты и осознанно оптимизировать технологические стадии. Наличие каверн свидетельствует о том, что упрочняющий модификатор попутно препятствует выходу газов из керамического тела. Поэтому необходимо корректировать режим обжига. Обнаружение трещиноватости указывает на несовершенство стадий сушки сырца и охлаждения после обжига.

Предложенная методика акустического тестирования керамических образцов позволяет правильно организовать их последующее испытание на прессе, оценить действие упрочняющей добавки и снизить издержки при промышленном масштабировании технологии соответствующих строительных материалов. Описанный подход может быть также полезен для технологии технической керамики. Для этой цели могут служить отечественные серийные измерители частот собственных колебаний типа ИЧСК-1, „Звук-130“, „Звук 203М“, а также иностранные приборы, например Grindo Sonic (Бельгия), после соответствующей аттестации разработанных специальных методик измерений и контроля. Представленные результаты неразрушающего контроля лабораторных образцов могут быть использованы в дальнейшем при переходе к контролю реальных изделий в производственных условиях.

\section{Финансирование работы}

Работа выполнена при поддержке Министерства образования и науки Российской Федерации (договор № 02.G25.31.0121, 2014гं.).

\section{Конфликт интересов}

Авторы заявляют, что у них нет конфликта интересов.

\section{Список литературы}

[1] Muñoz P.V., Morales M.P., Letelier V.G., Mendívil M.A. // Constr. Build. Mater. 2016. Vol. 125. P. 241-252. doi.org/10.1016/j.conbuildmat.2016.08.024

[2] Boltakova N.V., Faseeva G.R., Kabirov R.R., Nafikov R.M., Zakharov Y.A. // Waste Management. 2016. Vol. 60. P. 230246. DOI: $10.1016 /$ j.wasman.2016.11.008

[3] ГОСТ 23829-85. М.: Изд-во стандартов, 1986. 15 с.

[4] Коварская Е.3., Московенко И.Б. // В мире неразрушающего контроля. 2012. Т. 58. № 4. С. 13-16.

[5] ASTM C1259-15, Standard Test Method for Dynamic Young's Modulus, Shear Modulus, and Poisson's Ratio for Advanced Ceramics by Impulse Excitation of Vibration, ASTM International, West Conshohocken, PA (2015) www.astm.org

[6] ASTM C1198-09(2013), Standard Test Method for Dynamic Young's Modulus, Shear Modulus, and Poisson's Ratio for Advanced Ceramics by Sonic Resonance, ASTM International, West Conshohocken, PA (2013) www.astm.org

[7] ГОСТ 25714-83. М.: Изд-во стандартов, 1983.8 с.

[8] ГОСТ Р 52710-2007. М.: Изд-во. Стандартинформ, 2008. $17 \mathrm{c}$.

[9] ГОСТ 24332-88. М.: Изд-во стандартов, 1989. 17 с.

[10] Belli F., Radermacher F.J. / 5th International Conference, IEA/AIE-92. Proceedings. Springer Science \& Business Media, Paderborn, Germany. 1992. P. 123-126.

[11] Hertlin I., Rieth-Hoerst S. // Tile \& Brick International Manual. 2007. Verlag DVS.

[12] Bosomworth P. // Ceramic Industry. 2005. N 1. P. 20-24.

[13] Коварская Е.3., Московенко И.Б. // В мире неразрушающего контроля. 2015. Т. 68. № 2. С. 27-30.

[14] Ratle A., Lagacét M., Pandolfelli V., Allairet C., Rigaudt M. // J. of Canadian Ceramic Soc. 1996. Vol. 65. N 3. P. 202-204.

[15] Ondruška H. J., Podoba R., Trník A. // Вестник МГОУ. Сер. Физика-Математика. 2013. N 2. С. 54-63.

[16] Húlan T., Trník A., Medve' I., Štubña I., Kaljuvee T. // Thermophysics. 2016. AIP Conf. Proceed. 2016. Vol. 1752. P. 040009. https://doi.org/10.1063/1.4955240

[17] Faseeva G.R., Nafikov R.M., Lapuk S.E., Zakharov Yu.A., Novik A.A., Vjuginova A.A., Kabirov R.R., Garipov L.N. // Ceramics International. 2017. Vol. 43. N 9. P. 7202-7210. doi.org/10.1016/j.ceramint.2017.03.008

[18] Franco-Villafañe J.A., Flores-Olmedo E., Báez G., Gandarilla-Carrillo O., Méndez-Sánchez R.A. // Eur. J. Phys. 2012. Vol. 33. P. 1761-1769. doi:10.1088/01430807/33/6/1761

[19] Ерофеев В.И., Кажаев В.В., Семерикова Н.П. Волны в стержнях. Дисперсия. Диссипация. Нелинейность. М.: Физматлит, 2002. 208 с.

[20] ГОСТ 8462-85. М.: Изд-во Стандартов, 1987. 7 с.

[21] Barth M., Duckhorn F., Tschöke K., Tschöpe C., Köhler B. / 19th World Conference on Non-Destructive Testing. Munich. WCNDT 2016. http://www.ndt.net/article/wcndt2016/papers/we3f3.pdf

[22] Фасеева Г.Р., Набиков Р.М., Лапук С.Е., Захаров Ю.А., Киямов А.Г., Кабиров Р.Р., Гарипов Л.Н., Лядов Н.М., Файзрахманов И.А. // Стекло и керамика. 2017. № 12. C. 31-37.

[23] Фасеева Г.Р., Мумджи И.Э., Гилязов Л.Р., Нафиков Р.М., Захаров Ю.А., Кабиров Р.Р., Никитин С.И. // Вестник Казан. технолог. ун-та. 2017. Т. 20. Т 3. С. 68-71. 